\title{
Percepção ambiental da erosão costeira em uma praia no litoral do Nordeste do Brasil (Praia da Taíba, CE) *
}

\author{
Environmental awareness of coastal erosion of a beach \\ on the Coast of Northeast Brazil (Taiba Beach, CE)
}

\author{
Elana Carolina de Souza Medeiros ${ }^{\circledR,}$; ; Ana Flávia Pantalena ${ }^{1}$ \\ Brígida Miola $^{1}$; Renan Silva de Lima ${ }^{1}$; Marcelo de Oliveira Soares ${ }^{1}$
}

\begin{abstract}
RESUMO
A erosão costeira tem acarretado mudanças na paisagem de diversas praias, trazendo dificuldades para o desenvolvimento das atividades produtivas locais, como o turismo, a recreação e o comércio. Entretanto, comumente, as pesquisas não avaliam a percepção ambiental dos utilizadores das zonas costeiras, buscando um melhor entendimento a respeito das necessidades humanas e ambientais que compõem a realidade do local. Este estudo teve como objetivo realizar um diagnóstico da percepção dos usuários sobre a erosão costeira em uma praia turística no Nordeste do Brasil. Para isso, foram aplicados questionários adaptados à realidade local, divididos nas seguintes partes: informações sobre o entrevistado; formas de utilização da praia e percepção da paisagem. Os resultados mostraram uma concordância da maior parte dos entrevistados com o fato de a erosão costeira na área de estudo ser causada, principalmente, pela ação antrópica. As construções próximas ao mar e a construção de portos foram apontadas como as principais causas da instalação e intensificação dos processos erosivos locais, principalmente nos últimos cinco anos. Medidas de contenção à erosão costeira apontaram ser de importância significativa para melhorar a realidade socioeconômica e ambiental da área. Diante disso, nota-se a relevância da percepção ambiental aplicada a estudos de erosão costeira como ferramenta no planejamento de obras e/ou políticas que visem ao desenvolvimento sustentável e à recuperação de praias.
\end{abstract}

Palavras-chave: impactos costeiros, recuperação ambiental.

\begin{abstract}
The coastal zone, with its innumerable attractions, is considered a privileged destination for various purposes, including tourism, leisure, and residences. These activities are compromised when coastlines erode. Coastal erosion is a global problem, given the number of places around the world where the coastline is receding. For the coast of Northeast Brazil, which is highly significant for tourism due to its beautiful beaches, native communities, holiday resorts, and residences, coastal erosion is a serious environmental, economic, and social problem. Hence, this phenomenon must be addressed through an understanding of the physical processes involved in the erosion in accordance with the environmental awareness of the stakeholders of the coastal zones. This way, a better appreciation of the human and environmental needs that constitute the local reality and a better comprehension of the values and expectations of society regarding economic, ethical, and aesthetic issues for protection of the environment can be achieved. The aim of this study was to diagnose the perception of the stakeholders regarding coastal erosion on a tourist beach in the northeast of Brazil. Located $74 \mathrm{~km}$ from the capital of the state Ceará, the Praia da Taiba is an approximately $10 \mathrm{~km}$ stretch of sandy beach, dunes, and sandstone reefs, with many cliffs and gullies formed by the tidal hydrodynamics. In recent decades, the region has experienced economic boom due to tourism, the establishment of a port and industrial pole (the Industrial and Port Complex of Pecém (CIPP) in 2002), and the construction of wind turbines (the Eolic
\end{abstract}

\footnotetext{
@ Corresponding author: <elanacsm@yahoo.com.br>

${ }^{1}$ Universidade Federal do Ceará (UFC), Instituto de Ciências do Mar (LABOMAR). Avenida da Abolição, 3207, Fortaleza, CE, Brasil.
} 
Turbine Complex of Taiba in 1999). Data for the study was obtained using questionnaires specifically designed to reflect local reality. They were divided into the following parts: information about the interviewee, the ways people use the beach, and people's perception of the landscape. The results showed that the majority of the interviewees agreed that coastal erosion in the study area was caused by human activities, mainly related to the port complex of Pecém, over the last five years. Measures to contain coastal erosion were considered important in improving the socioeconomic state of the area. As a result, environmental awareness is relevant in studies of coastal erosion as a tool for planning and/or policies of public works that endeavor to improve beaches by controlling coastal erosion with the ultimate aim of contributing to socioeconomic and environmental development and the recuperation of tropical beaches.

Keywords: coastal impacts, environmental recuperation.

\section{Introdução}

A zona costeira, devido a seus inúmeros atrativos, é considerada um espaço privilegiado para os mais diversos propósitos, como turismo, lazer e moradia. Essas atividades tornam-se comprometidas quando o litoral em questão está submetido a processos de erosão costeira. Esse fenômeno é considerado um problema global, visto que diferentes locais no mundo apresentam recuo da linha de costa, acarretando sérios prejuízos para a comunidade litorânea (Bird, 1993; Calliari et al., 2003; Muehe, 2006).

Para o estado do Ceará, reconhecido pelo potencial turístico litorâneo devido às belas praias, às comunidades nativas, aos polos de lazer e às segundas residências (Coriolano, 2008), a erosão costeira configura-se como um grave problema de cunho ambiental, econômico e social.

Segundo Farias \& Maia (2010), há uma tendência quase geral de avanço do mar no litoral do estado do Ceará que vem promovendo a destruição de casas e estruturas de defesa do litoral.

A Praia da Taíba (Figura 1), localizada no litoral oeste do estado do Ceará, é um exemplo dessa problemática. Além da perda do valor paisagístico devido aos prejuízos visíveis, como a destruição do patrimônio público e privado, a erosão costeira tem sido responsável pela queda no valor dos imóveis e por gastos exorbitantes com a mitigação do avanço do mar. A perda considerável de faixa de praia tem ocasionado prejuízos às atividades socioeconômicas e comprometido o potencial turístico local (Souza, 2009) (Figura 2).

Com isso, a erosão das praias passou a ser tratada não apenas do ponto de vista do entendimento dos processos físicos, mas também sob um enfoque social. A percepção ambiental dos utilizadores dessas zonas costeiras pode auxiliar nesse enfoque, pois busca uma melhor compreensão das necessidades humanas e ambientais que compõem a realidade do local (Barros, 2005).

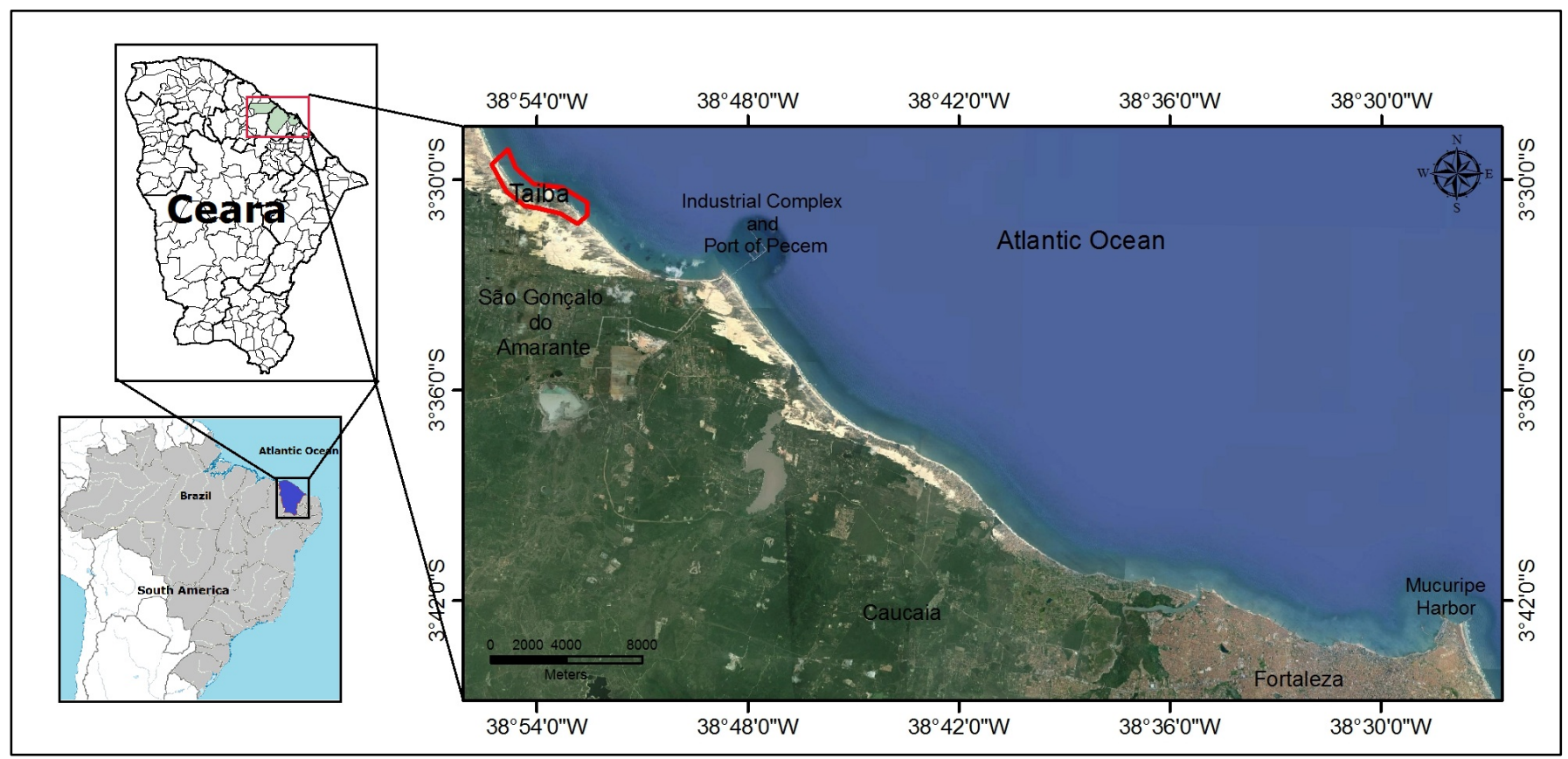

Figura 1 - Mapa de localização da Praia da Taíba.

Figure 1 - Location map of Taiba Beach. 


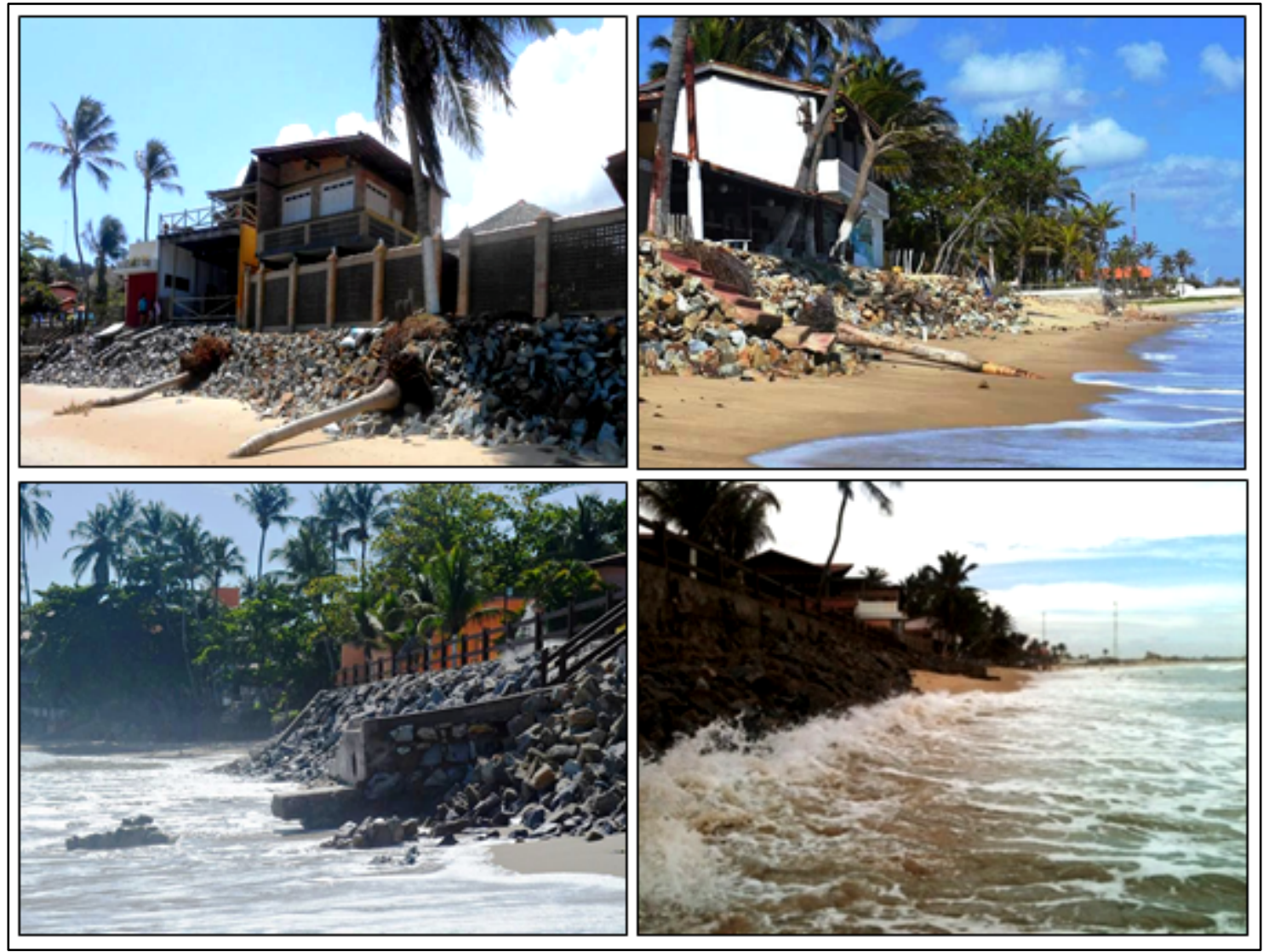

Figura 2 - Imagens dos impactos da erosão costeira na Praia da Taíba.

Figure 2 - Imagens of the impacts of the coastal erosion of the beach of Taiba.

O estudo da percepção ambiental é de fundamental importância para que possamos compreender as interrelações entre o homem e o meio, os valores e as expectativas da sociedade na busca por qualidade da paisagem e do ambiente (Palma, 2005; Souza, 2009; Fernandes \& Sansolo, 2013). Diante disso, estudos dessa vertente, como, por exemplo, Morgan (1993); Priskin (2003), Marin (2008), Roca et al. (2009) e Bittencourt (2011), podem ser considerados excelentes referências para a gestão costeira, funcionando como elementos de sensibilização para uma consciência ambiental.

Dada a importância das zonas costeiras no enfoque socioeconômico brasileiro, esta pesquisa justifica-se por identificar os impactos que problemas erosivos causam, através da vivência e experiência do utilizador local. A adoção dessa abordagem pode contribuir com o reconhecimento do valor da sociedade civil como agente transformador capaz de nortear e efetivar as ações de políticas públicas nas zonas costeiras.

Nesse contexto, o presente trabalho objetiva realizar um diagnóstico da percepção ambiental dos usuários sobre a erosão costeira, apontando: 1) impactos socioeconômicos em função dos processos erosivos; 2) causas e consequências da erosão costeira; 3) expectativas quanto à recuperação da qualidade de praia.

\section{Materiais e métodos}

\section{1. Área de estudo}

A Praia da Taíba está localizada no estado do Ceará, nordeste do Brasil (Figura 2), e tem como vias de acesso rodoviário a CE-085 e a CE-156, distando aproximadamente $70 \mathrm{~km}$ da cidade de Fortaleza, capital do estado. Apresenta $10 \mathrm{~km}$ de extensão de praia arenosa, dunas e recifes de arenitos, possuindo muitas falésias com reentrâncias formadas pelo hidro-dinamismo das marés (Paiva \& Macedo, 1997).

Dentre as principais atividades econômicas da região do município de São Gonçalo do Amarante, destacam- se a agricultura de subsistência, a agroindústria canavieira, a indústria de cerâmica, o artesanato e o comércio varejista (Araújo et al., 2009). Porém, nas últimas décadas, a região teve sua economia impulsionada pelo turismo, pela construção do porto e pelas usinas eólicas. O município abriga o Complexo Industrial e Portuário do Pecém (CIPP), instalado desde 2002, que fica a cerca de $10 \mathrm{~km}$ da praia da Taíba. Na região, localiza-se também a Central Eólica da Taíba, em operação desde 1999.

O distrito da Praia da Taíba possui uma população de 5.104 habitantes (Instituto Brasileiro de Geografia e Estatística - IBGE, 2010), apresentando um crescimento populacional de $23,37 \%$ em relação ao censo de 2000 (Ferla \& Lehugeur, 2007). 
Caracteriza-se por ser uma praia com significante atração para veranistas, devido a sua beleza cênica e infraestrutura, além de ser muito utilizada para a prática de esportes náuticos e de atividades pesqueiras. E por sua condição de acesso, suas boas casas de veraneio e sua proximidade do Pecém, a Praia da Taíba está abrigando um grande contingente de trabalhadores do CIPP que fixaram residências temporárias na sua área urbana (INESP/CAECE, 2013).

\subsection{Metodologia de trabalho}

As técnicas de estudo de percepção ambiental são formadas pela combinação de três métodos básicos: observar, escutar e fazer perguntas (Fernandes \& Sansolo, 2013). Para alcançar essa combinação de métodos, inicialmente, foram feitos levantamentos de dados em função da dinâmica da Praia da Taíba, através de: 1) referencial bibliográfico; 2) visitas a campo (observação das formas de uso, ocupação e acessibilidade da praia); e 3) conversas com os usuários da localidade (oralidade referente ao avanço do mar e suas consequências para a população da área em questão). Com isso, foi possível a elaboração de perguntas relevantes sobre o tema a ser abordado, por meio de um questionário adaptado à realidade local.

O questionário é considerado um dos instrumentos mais utilizados na investigação social, sobretudo nos estudos de percepção da paisagem, como realizado por Silva (2002), Dias Filho et al. (2011) e Santana Neto et al. (2011). Assim, a aplicação de questionários possibilitou tanto a caracterização do perfil socioeconômico dos usuários quanto a avaliação da sua percepção ambiental sobre a erosão costeira e seus impactos. O questionário foi dividido nas seguintes partes: 1) informações sobre os entrevistados (dados sociodemográficos, permitindo traçar o perfil do usuário); 2) formas de utilização da praia (tipo de relação usuário e ambiente); e 3) percepção da paisagem (a percepção dos usuários em relação à problemática da erosão costeira, bem como sugestões de melhorias na qualidade de praia).

Os entrevistados foram abordados na faixa de praia, nas ruas e nos calçadões que dão acesso à Praia da Taíba durante os fins de semana do mês de junho de 2013. Correspondeu a um conjunto de 75 entrevistados, composto pelos segmentos de moradores, comerciantes locais e frequentadores assíduos (banhistas/excursionistas e esportistas). A opção de não considerar turistas como parte da amostra se deve à necessidade de certa familiaridade com o ambiente (Roca et al., 2009), uma vez que apenas pessoas que visitam a Praia da Taíba com mais frequência ou há muitos anos seriam capazes de observar as mudanças no espaço em escala temporal.

Os procedimentos estatísticos dos dados foram tratados no software SPSS - Statistical Package for Social
Sciences e Excel versão 2010, com vistas a facilitar a edição e apresentação gráfica dos resultados obtidos.

\section{Resultados e discussões}

\subsection{Perfil dos Entrevistados}

O perfil dos entrevistados foi, sobretudo, de freqüentadores assíduos, seguidos de moradores e comerciantes locais. Desse conjunto, a maioria (68\%) dos entrevistados foram do sexo masculino, pertencentes à menor faixa etária (entre 18 e 29 anos) e solteiros quanto ao estado civil.

No que concerne ao grau de escolaridade e à renda familiar, observa-se que a maior parte dos respondentes possui ensino superior completo ou incompleto e renda familiar entre $\mathrm{R} \$ 2.400$ e $\mathrm{R} \$ 4.800$. Essa caracterização socioeconômica dos usuários está intimamente ligada ao maior percentual de frequentadores assíduos oriundos da capital Fortaleza, o que remete a pessoas com maior grau de escolaridade e poder aquisitivo, se comparado aos entrevistados oriundos da Praia da Taíba. Porém, uma amostra significativa, representada pelos moradores e comerciantes, possui ensino médio completo ou incompleto e renda familiar entre $\mathrm{R} \$ 600$ e $\mathrm{R} \$ 1.200$, semelhante aos resultados encontrados por Sousa et al., (2008) e Araújo \& Maia (2011) referentes ao perfil socioeconômico em praias na zona costeira cearense. A Figura 3 mostra o perfil socioeconômico dos usuários da Praia da Taíba.

\subsection{Formas de Utilização da Praia da Taíba}

Quanto à familiaridade com a Praia da Taíba, observase que $76 \%$ dos respondentes frequentam a praia há no mínimo dez anos; com frequência de Somente nos Fins de Semana, seguido por Diariamente, permanecendo entre duas a três horas em cada visita (Figura 4). Como principais atividades realizadas, destacam-se a Prática de Esportes, seguida pela ação de Descansar e Desfrutar da Paisagem. Dentre as modalidades esportivas, o Surf e o Kitesurf foram os esportes mais praticados na área de estudo (Figura 5).

As atividades praticadas, como também o tempo e a frequência de visita à Praia da Taíba permitem avaliar a dinâmica social da praia e o conhecimento dos seus utilizadores com relação às transformações ocorridas ao longo dos anos e aos impactos dessas transformações em suas experiências de praia.

Portanto, além da importância cênica, o potencial de uso da Praia da Taíba está ligado à prática de esporte e lazer, típicas do litoral, também observado por Venson (2009) e Silva (2002). No caso deste estudo, a maioria dos respondentes possui um tempo consideravelmente longo de visita a essa praia ao ponto de estar famíliarizado com as transformações decorrentes da erosão costeira na área de interesse. 


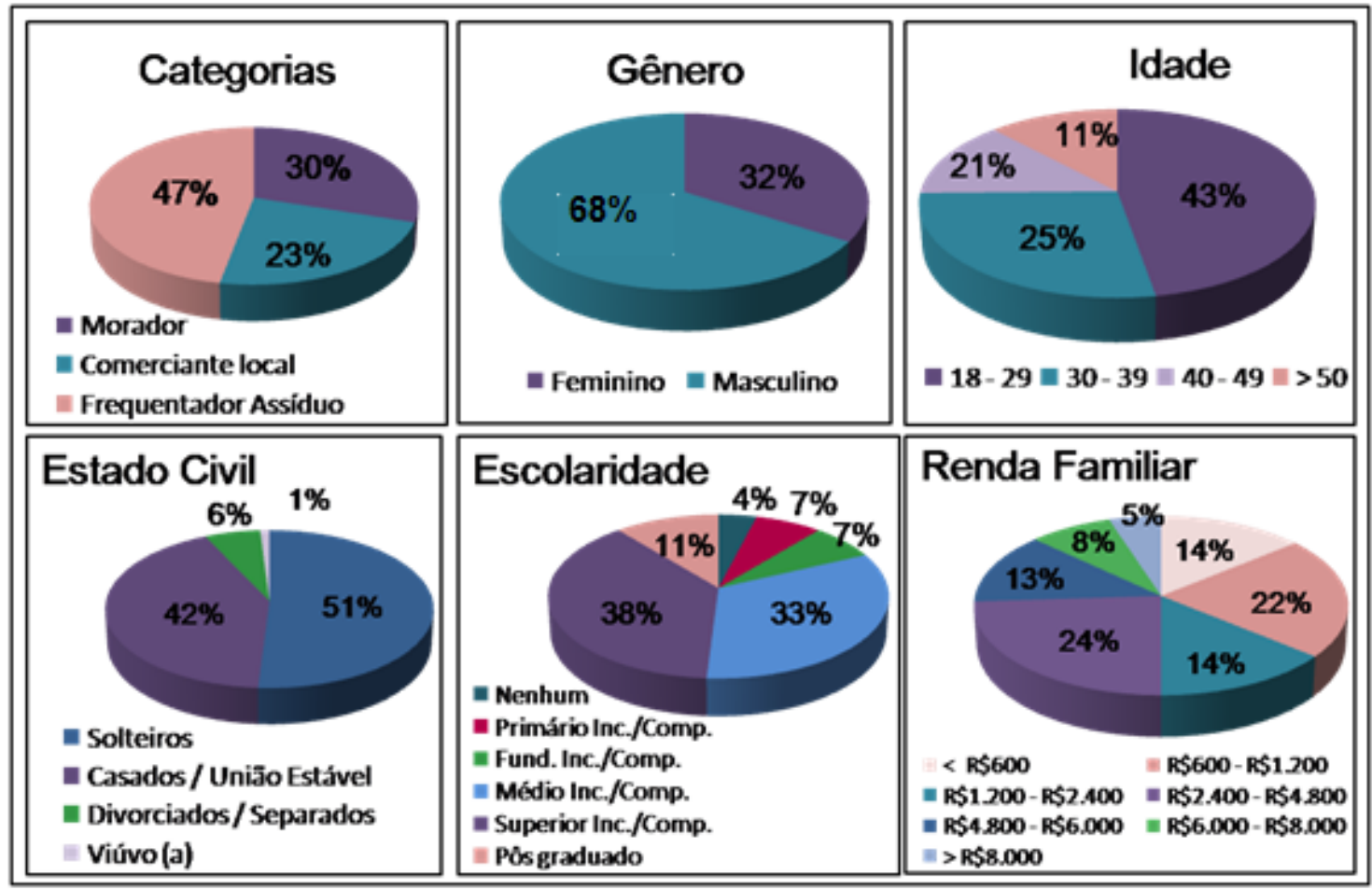

Figura 3 - Perfil socioeconômico dos entrevistados.

Figure 3 - Socioeconomic profile from the interviewees.

\begin{tabular}{|c|c|c|}
\hline 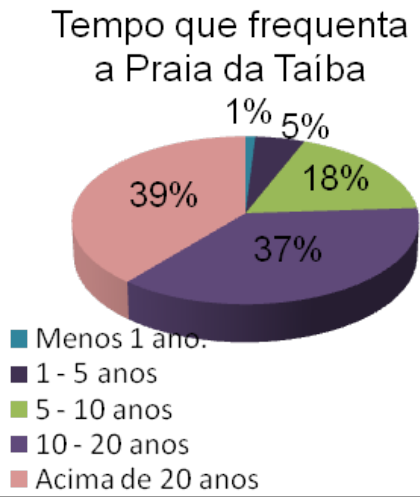 & $\begin{array}{l}\text { Frequencia semanal } \\
\text { a Praia da Taíba } \\
\text { - } 1 \text { vez/ semana } \\
\text { - Mais de } 2 \text { vezes/semana } \\
\text { - Mais de quatro vezes/semana } \\
\text { - Diariamente } \\
\text { - Somente nos fins de semana } \\
\text { - Raramente }\end{array}$ & $\begin{array}{l}\text { Tempo de permanência } \\
\text { a cada visita } \\
9 \% \quad 13 \% \quad 9 \%\end{array}$ \\
\hline
\end{tabular}

Figura 4 - Distribuição do número de anos que os respondentes visitam, distribuição da frequência semanal e o tempo de cada visita à Praia da Taíba.

Figure 4 - Distribution of the number of years which the interviewees visits, frequency distribution of the weekly visits and the time each visit takes to Taiba Beach.

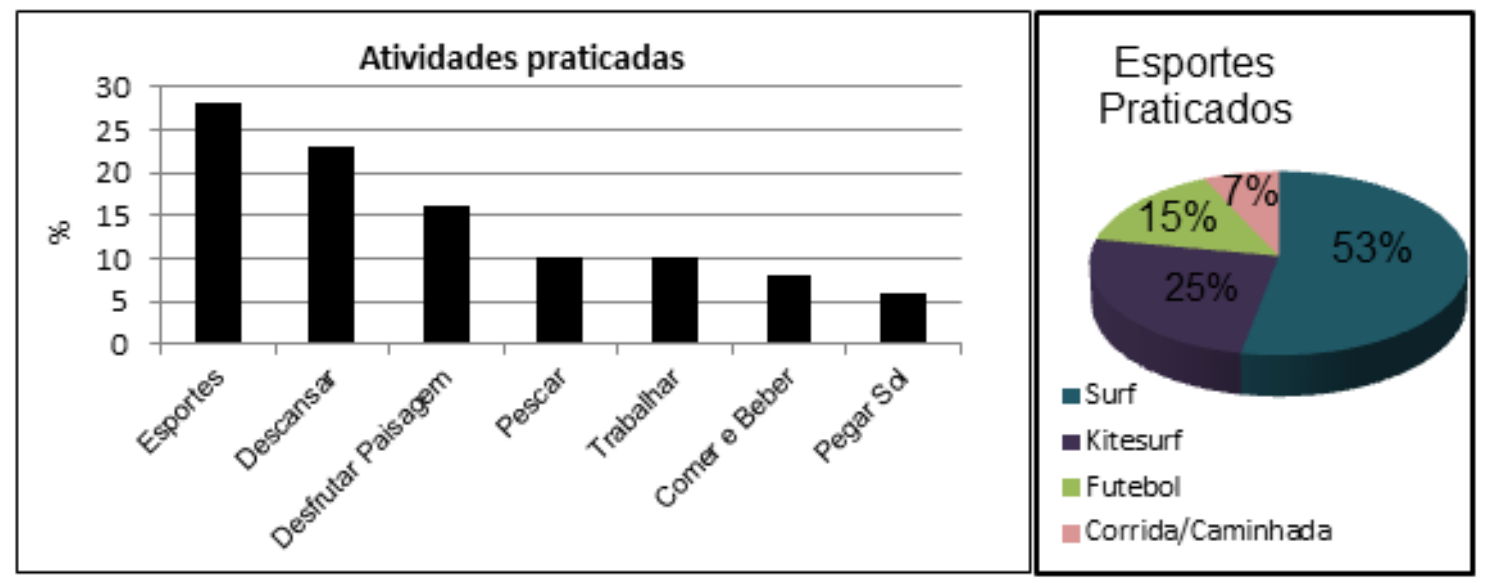

Figura 5 - Atividades praticadas e modalidades esportivas.

Figure 5 - Activities and sports practiced. 


\subsection{Percepção da Paisagem}

No que tange aos principais atrativos da área de estudo, destacam-se Beleza Natural, Tranquilidade e Praia Favorável a Práticas de Esportes (Figura 6).

A respeito dos maiores problemas enfrentados nessa praia, atributos relacionados a fenômenos erosivos foram os mais citados, como Avanço do Mar e Problemas Causados pela Erosão Costeira, demonstrando, assim, a sensibilidade da área em função dos problemas erosivos e suas consequências (Figura 7). Esse fato também fica evidenciado quanto ao grau de importância atribuído aos problemas causados pela erosão costeira na Praia da Taíba, com 91\% da amostra atribuindo valores máximos, ou seja, Muito Importante e Importante, a essa problemática (Figura 8).

Quando questionados acerca do quanto a erosão costeira afetou as atividades praticadas na Praia da Taíba, $84 \%$ dos respondentes se dizem, de alguma forma, impactados pelo problema. Desses, a maioria declara-se Muito Afetados, seguida por Razoavelmente Afetados e Pouco Afetados (Figura 9).

No que tange ao grau de esclarecimento dos usuários da Praia da Taíba referente às causas e consequências da erosão costeira, foram apresentadas aos respondentes afirmativas sobre a temática às quais eles podiam se posicionar a favor, contra ou neutro (Tabela 1 ).

A partir daí, observa-se que, para $82 \%$ da amostra, $a$ Erosão Costeira é em Grande parte Causada pelo Homem. Fato corroborado devido a $73 \%$ de a amostra concordar que Obras ao Longo do Litoral Intensificam os Processos Erosivos. A ação antrópica também é citada entre os principais fatores responsáveis pela instalação e intensificação dos processos erosivos na área de estudo, com Construção de Portos (36\%), referente ao CIPP, e Construções próximas ao mar (25\%) destacando-se como razões causadoras desse fenômeno (Figura 10).

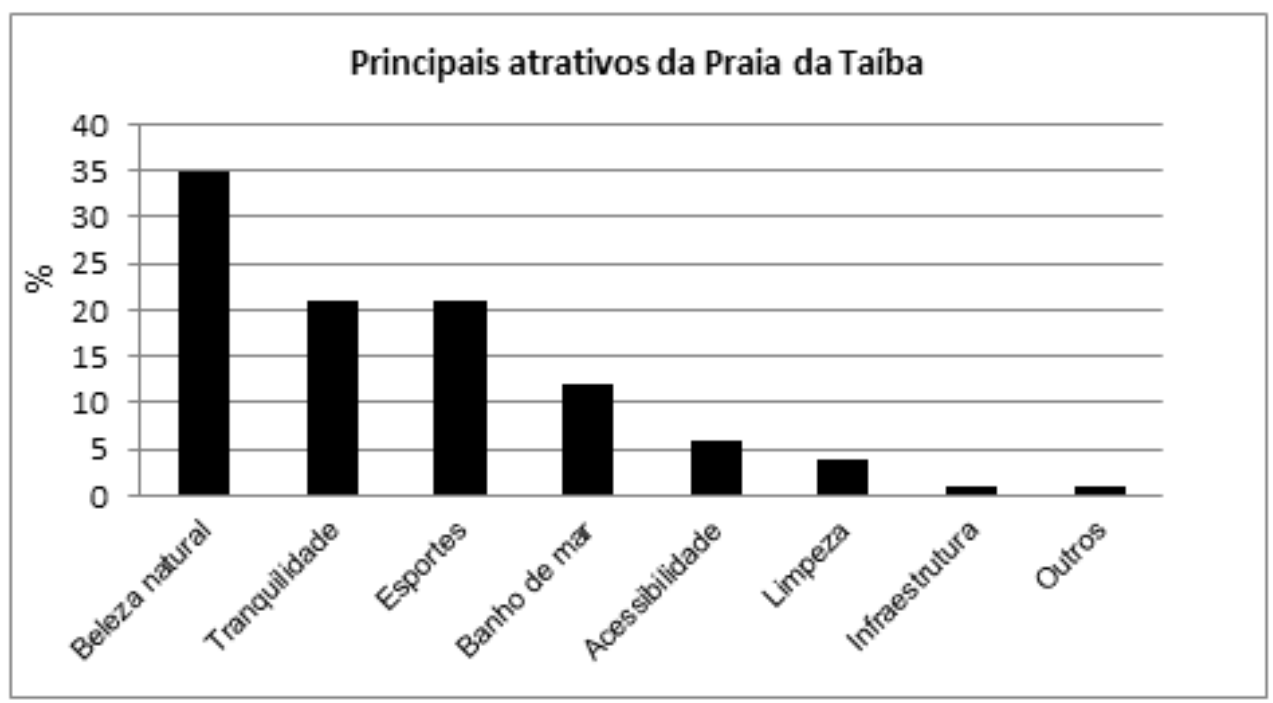

Figura 6 - Principais atrativos da Praia da Taíba.

Figure 6 - Main attractives of Taiba Beach.

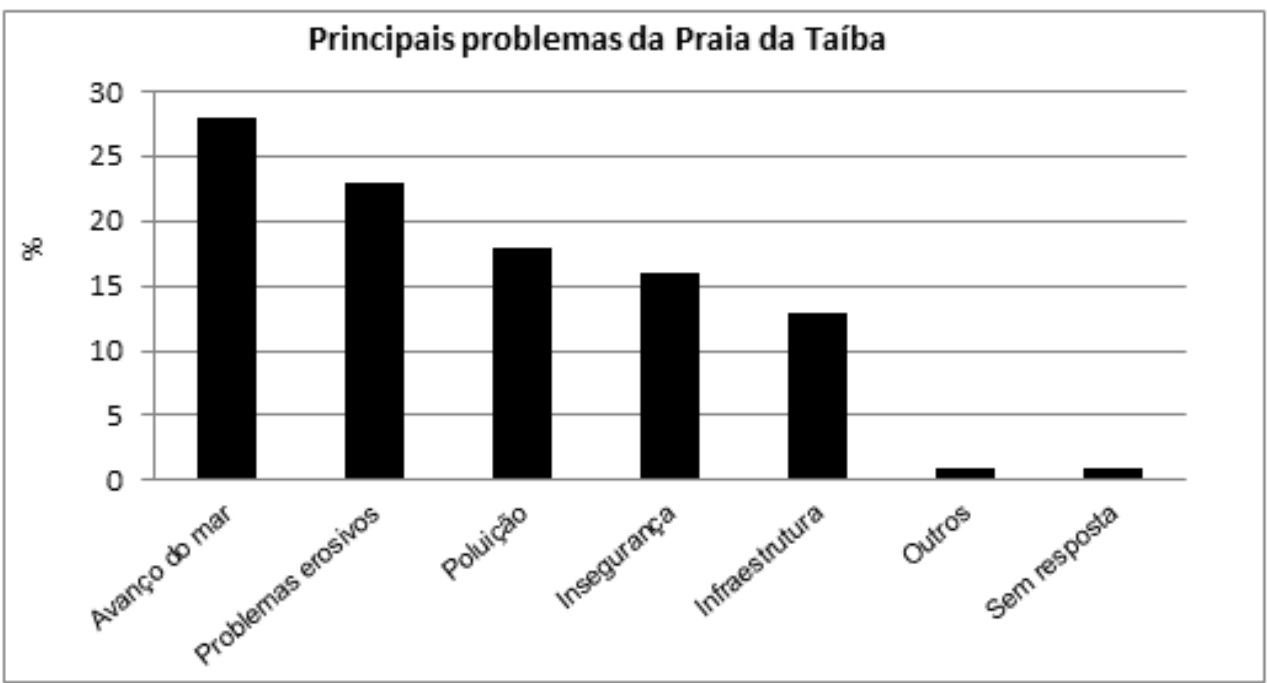

Figura 7 - Principais problemas da Praia da Taíba.

Figure 7 - Main problems of the beach of Taiba 


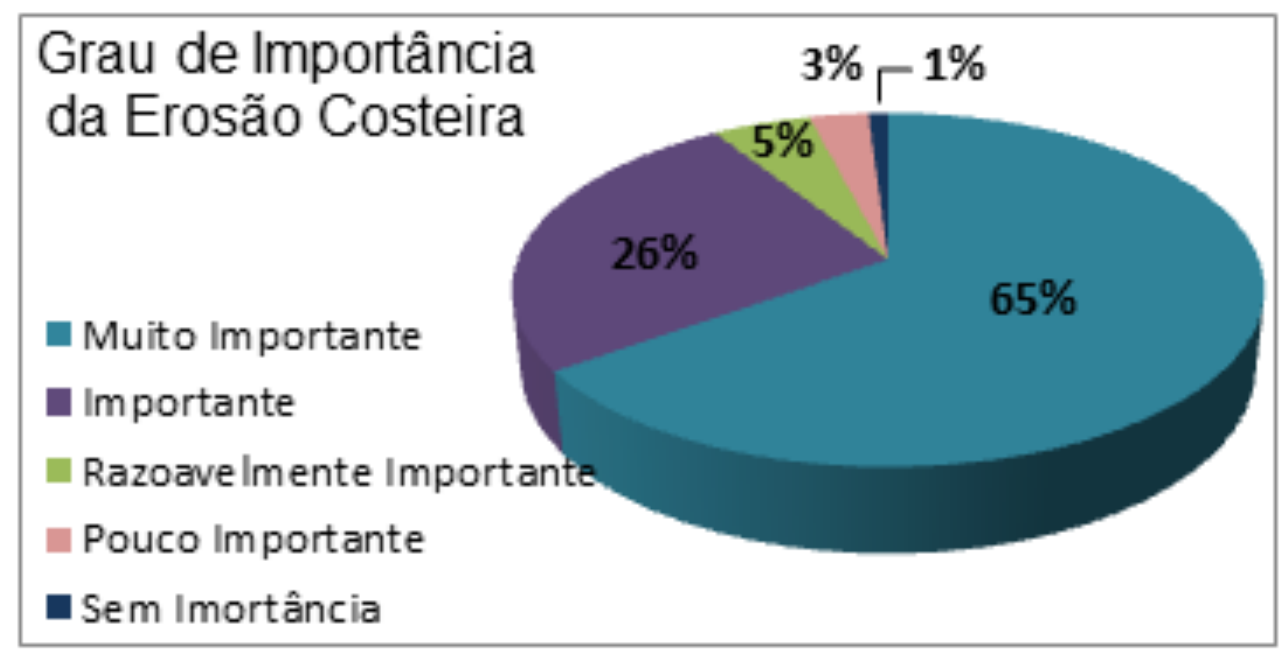

Figura 8 - Grau de importância em relação aos problemas causados pela erosão costeira na Praia da Taíba.

Figure 8 - Degree of importance in relation of problems caused by coastal erosion on Taiba Beach.

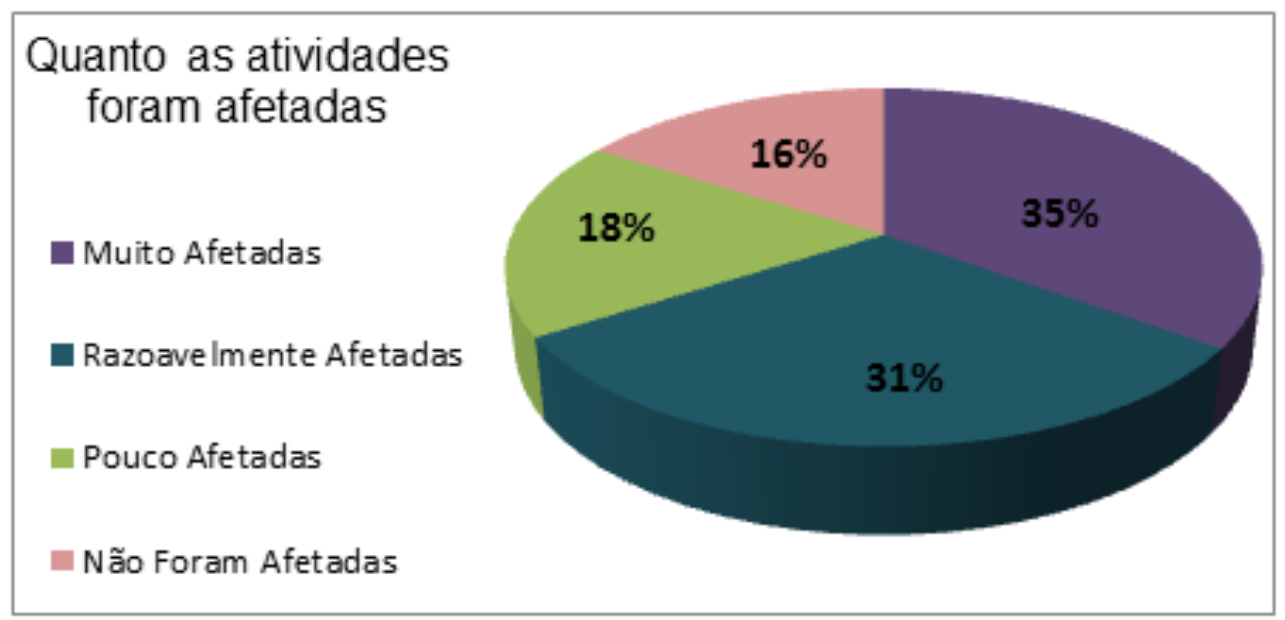

Figura 9 - Nível de interferência nas atividades dos usuários provocada pela erosão costeira na Praia da Taíba.

Figure 9 - Interference level in the activities of users caused by coastal erosion on Taiba Beach.

Tabela 1 - Concordância em relação às afirmativas sobre erosão costeira.

Table 1 - Agreement regarding statements about coastal erosion.

\begin{tabular}{|c|c|c|c|}
\hline Afirmativas & D* & NDNC** & $\mathbf{C} * * *$ \\
\hline 1- A erosão costeira é em grande parte causada pelo homem; & $\begin{array}{c}6 \\
(8 \%)\end{array}$ & $\begin{array}{c}7 \\
(9 \%)\end{array}$ & $\begin{array}{c}61 \\
(82 \%)\end{array}$ \\
\hline 2 - Obras ao longo do litoral não intensificam os processos erosivos; & $\begin{array}{c}53 \\
(73 \%)\end{array}$ & $\begin{array}{c}10 \\
(14 \%)\end{array}$ & $\begin{array}{c}10 \\
(14 \%)\end{array}$ \\
\hline 3 - A erosão costeira não afasta o turista da praia; & $\begin{array}{c}58 \\
(78 \%)\end{array}$ & $\begin{array}{c}8 \\
(11 \%)\end{array}$ & $\begin{array}{c}8 \\
(11 \%)\end{array}$ \\
\hline $\begin{array}{l}4 \text { - As obras de contenção a erosão costeira prejudicam a paisagem } \\
\text { da praia; }\end{array}$ & $\begin{array}{c}7 \\
(9 \%)\end{array}$ & $\begin{array}{c}9 \\
(12 \%)\end{array}$ & $\begin{array}{c}58 \\
(78 \%)\end{array}$ \\
\hline $\begin{array}{l}5 \text { - Prefiro perder parte da beleza paisagística devido às obras de } \\
\text { contenção a erosão do que ter uma praia com graves processos }\end{array}$ & $\begin{array}{c}14 \\
(19 \%)\end{array}$ & $\begin{array}{c}18 \\
(25 \%)\end{array}$ & $\begin{array}{c}41 \\
(56 \%)\end{array}$ \\
\hline
\end{tabular}

Nota: D* $^{*}$ Discorda; NDNC** : Nem discorda nem concorda; e C*** : Consorda 


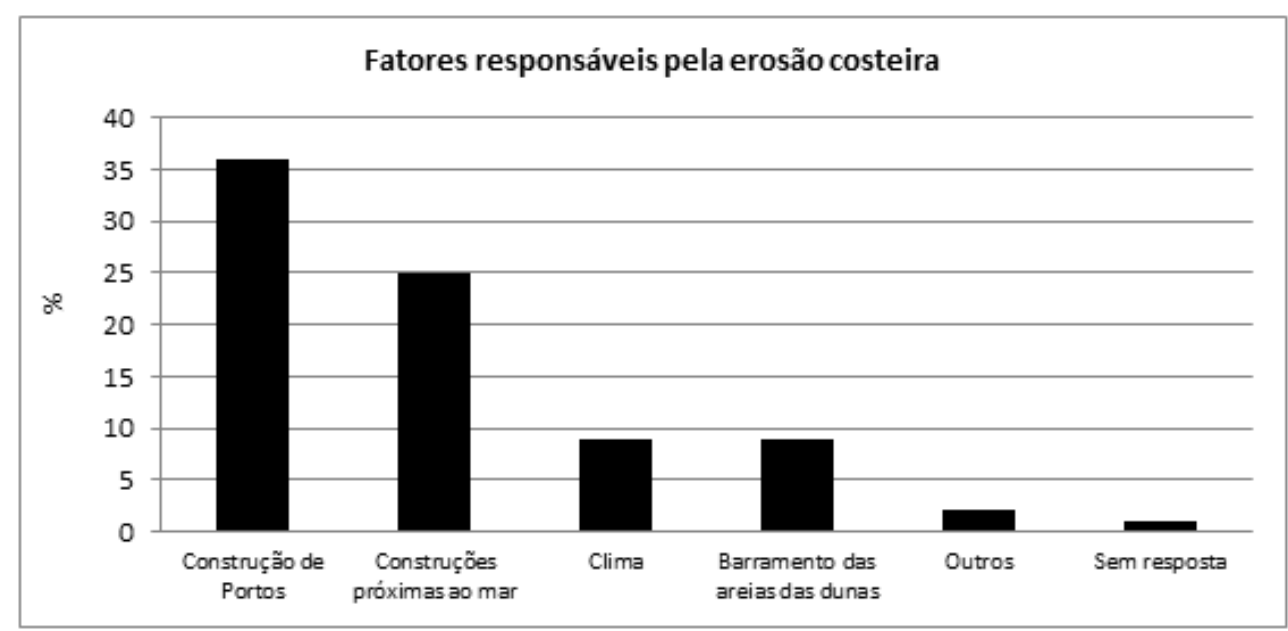

Figura 10 - Principais fatores responsáveis pela erosão costeira na Praia da Taíba.

Figure 10 - Main factors responsible for coastal erosion on Taiba Beach.

Esses resultados corroboram com estudos realizados na costa leste do Canadá (Friesinger \& Bernatchez, 2010), onde mais de $50 \%$ dos entrevistados acreditam que as modificações antropogênicas na região são as principais causadoras da erosão local.

O Terminal Portuário do Pecém (TPP), inaugurado oficialmente em 2002, integra o CIPP. A sua implantação teve como objetivo viabilizar a operação de atividades portuárias e industriais integradas, imprescindíveis ao desenvolvimento de um complexo com características de porto industrial (Nogueira et al., 2005).

O CIPP possui aproximadamente $200 \mathrm{~km}^{2}$ de extensão, englobando parte dos municípios de São Gonçalo do Amarante e Caucaia (ambos pertencentes à Região Metropolitana de Fortaleza), e, também, localização geográfica privilegiada em relação aos principais mercados de consumo internacionais (Europa e EUA). Tem sua maior parte do complexo $\left(116 \mathrm{~km}^{2}\right)$ situado no distrito de Pecém, cerca de $10 \mathrm{~km}$ a leste da Praia da Taíba (Araújo et al., 2009). Segundo Vieira et al. (2007), um terminal portuário em costas de areia, como no caso do TPP, proporciona uma área de amortecimento energético ondulatório, gerando um possível local de acumulação de areia. Com isso, sedimentos que seguiriam o transporte longitudinal ficam aprisionados em um ponto especial, causando um desequilíbrio sedimentar ao longo da costa, com assoreamento a barlamar do molhe construído e erosões a sotamar.

Após a implantação do TPP, a Praia do Pecém sofreu um engordamento na ordem de $60 \mathrm{~m}$ provocado pela diminuição das forças dos fatores ambientais que modelam a costa (ondas, correntes e marés), acarretando áreas de sedimentação na orla do Pecém (Magini et al., 2011). Porém, Araújo et al. (2009) chamam a atenção para os impactos da edificação do porto do Pecém na dinâmica costeira e seus efeitos negativos em praias vizinhas, no caso, referente à Taíba.
Magini et al. (2011) realizaram um estudo de perfis de praia na localidade do TPP entre 2005 e 2009 para avaliar mudanças na dinâmica praial em função da área portuária. Foi observada uma progradação da linha de costa em escala crescente para todos os anos do estudo, chegando a mais da centena de metro (110m em setembro de 2008) nalguns perfis.

Concomitantemente ao período amostral no estudo de Magini et al. (2011), são observadas a instalação e a intensificação dos processos erosivos na Praia da Taíba por parte dos seus frequentadores, com $87 \%$ da amostra total observando essa problemática nos últimos 10 anos (referente ao período de operação do TPP). Dessa amostra, 66\% indicam que a erosão agravou-se nos últimos cinco anos, ou seja, entre 2008 a 2013 (Figura 11).

Com relação às consequências que a erosão costeira pode causar em uma praia, observam-se impactos no setor socioeconômico local, visto que o turismo é uma das principais fontes de renda das comunidades litorâneas do estado do Ceará. No caso da Taíba, a erosão costeira causa sérios prejuízos ao turismo local devido à destruição das infraestruturas aptas a atender os visitantes, acarretando depreciação visual devido aos entulhos dessas obras a beira-mar, além de perdas em áreas destinadas ao lazer público.

A respeito da percepção dos usuários em relação aos danos sofridos pelo turismo, observa-se que mais de $78 \%$ da amostra concorda que a erosão costeira prejudica o turismo de uma praia. Essa frequência é notada, justamente, por discordar da afirmativa $A$ Erosão Costeira Não Afasta o Turista da Praia.

A respeito do impacto visual que intervenções contra a erosão costeira causam na paisagem do ambiente litorâneo, 78\% dos respondentes concordam que as Obras de Contenção à Erosão Costeira Prejudicam a Paisagem da Praia. Isso se dá ao fato de a maioria das obras de contenção à erosão costeira destoar do ambien- 


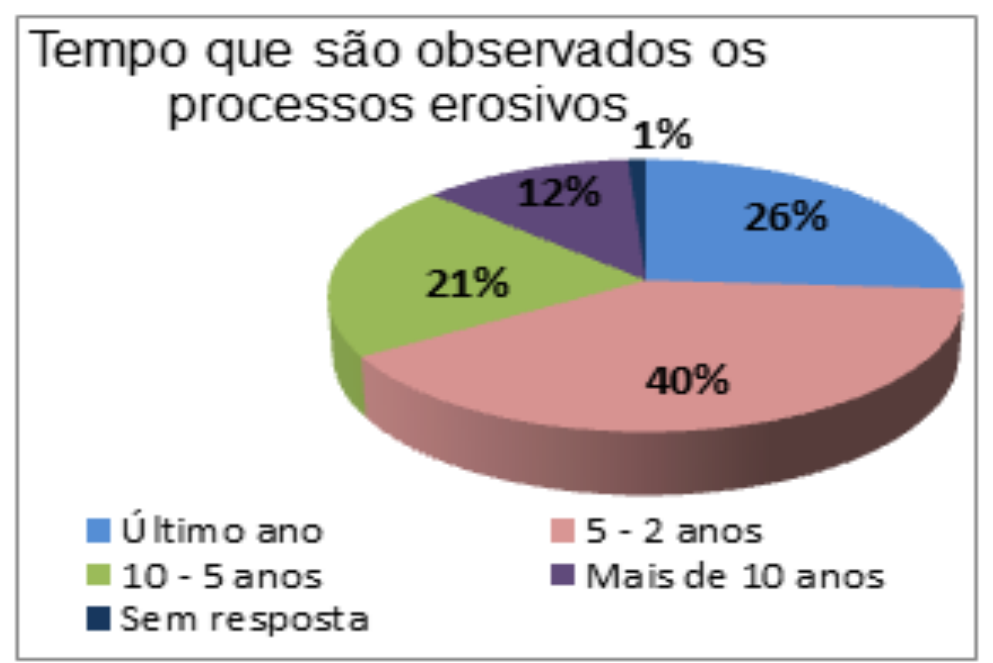

Figura 11 - Tempo em que são observados os processos erosivos na Praia da Taíba.

Figure 11 - Time that erosion processes are observed on Taiba. Beach.

te natural de uma praia, como observado em algumas intervenções no estado do Ceará, como, por exemplo, espigões e muros de proteção (Farias \& Maia, 2010). Outras obras de contenção à erosão costeira apresentam menor depreciação visual, por utilizarem a matériaprima natural do próprio ambiente, como a engorda de praia, ou tornam-se o mínimo visível possível, como quebra-mar submerso.

Mesmo com a maioria concordando que as obras de contenção à erosão costeira prejudicam a paisagem do lugar, ainda assim, uma maior parte da amostra prefere Perder Parte da Beleza Paisagística Devido às Obras de Contenção à Erosão do que Ter uma Praia com Graves Processos Erosivos.

Nesse caso, tratando-se da Praia da Taíba, evidencia-se que obras de controle ao avanço do mar são importantes para seus usuários, indicando que estes são receptivos às tomadas de decisões que resultem em melhorias no local, contribuindo em prol da conservação da área. Esse fato é corroborado devido a praticamente $90 \%$ da amostra atribuir valores máximos de importância em relação ao controle da erosão costeira na Praia da Taíba (Figura 12).

Tendo como referência a situação atual da área de estudo, perguntou-se aos respondentes qual o grau de importância de ações de melhorias para a experiência de lazer e moradia na Praia da Taíba. Essas melhorias esperadas pelos usuários podem servir de base para orientar as prioridades de um planejamento de gestão da praia.

Em conjunto, todas as medidas de melhorias foram avaliadas pela maioria significativa dos usuários (91\%) quanto à sua importância como Importantes ou Muito Importantes. Em ordem decrescente de importância, as

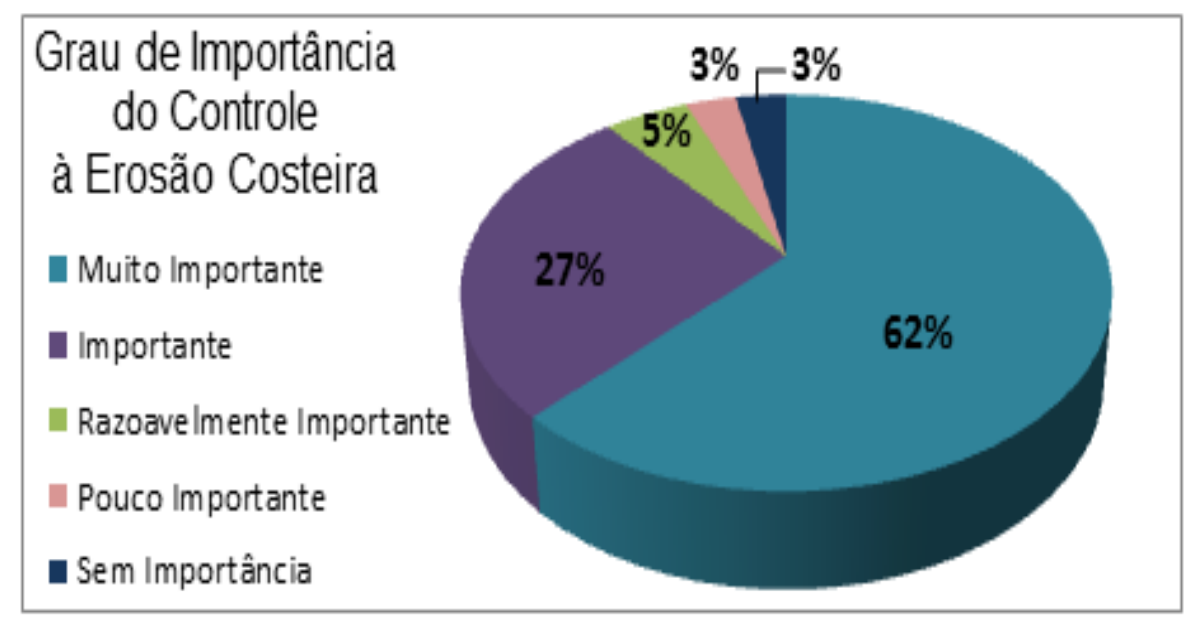

Figura 12 - Grau de importância em relação ao controle à erosão costeira na Praia da Taíba.

Figure 12 - Degree of importance in relation to the control of coastal erosion on Taiba Beach. 


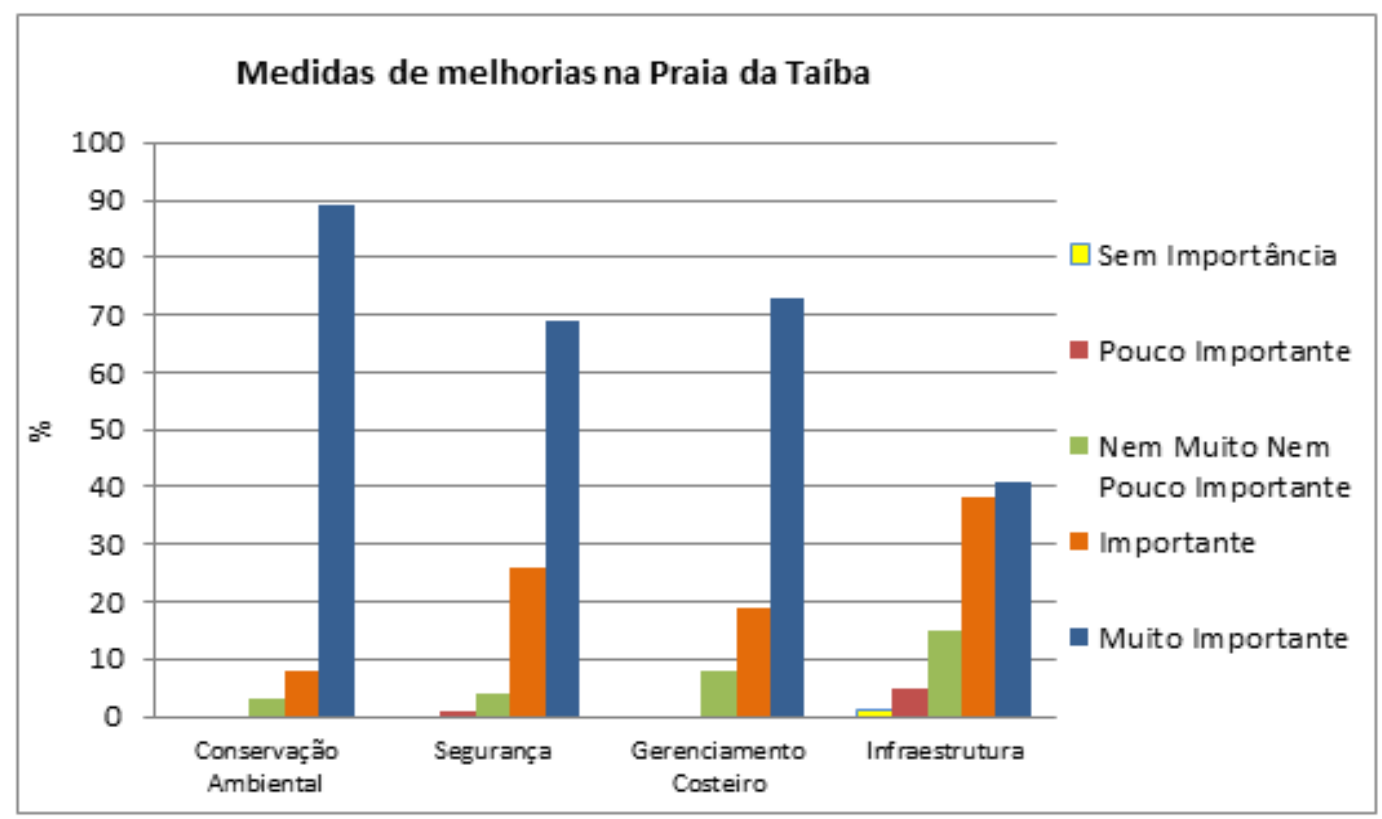

Figura 13 - Grau de importância das medidas de melhorias para a Praia da Taíba.

Figure 13 - Importance degree of the improvement measures to the beach of Taiba

medidas apresentaram a seguinte sequência: Melhoria na Conservação Ambiental - limpeza da praia, educação ambiental (97\%); Melhoria na Segurança mais policiamento, salva-vidas (95\%); Melhoria no Gerenciamento Costeiro Contra a Erosão - efetivar projetos de combate à erosão (92\%); Melhoria na Infraestrutura - quiosques, equipamentos de praia, banheiros, chuveiros e etc. (79\%).

Diante disso, as políticas visando à melhoria da qualidade da praia e das experiências de recreação e lazer devem ser direcionadas para um manejo eficiente de resíduos sólidos, conscientização ambiental, segurança e controle à erosão costeira, principalmente. A Figura 13 mostra as medidas de melhorias e seus respectivos percentuais quanto ao grau de importância atribuído pelos usuários da Praia da Taíba.

Portanto, analisar a percepção dos usuários da Praia da Taíba a respeito das potencialidades e problemáticas locais torna-se de fundamental importância na compreensão da realidade desse litoral. Essa percepção pode auxiliar no planejamento da área, aumentando a confiabilidade para tomadas de decisões baseadas nas opiniões e atitudes dos próprios usuários do recurso, podendo, assim, direcionar medidas de gestão na zona costeira em prol de um melhor uso do ambiente.

\section{Considerações finais}

O presente estudo buscou diagnosticar a percepção ambiental dos usuários da Praia da Taíba - CE a respeito da erosão costeira e seus impactos nas experiências de praia dos seus frequentadores, bem como apontar sugestões para futuras ações governamentais que possam ser adotadas para melhorar a qualidade de vida dos moradores e utilizadores desse importante recurso natural cearense.

Em um contexto geral, a maioria dos entrevistados residem ou frequentam há um tempo consideravelmente longo o local e afirmam estarem familiarizados com as transformações decorrentes da erosão costeira e seus impactos diretos nos potenciais de uso da praia, na prática de esporte e lazer, além de em sua beleza natural.

$\mathrm{O}$ aspecto de qualidade e impacto ambiental sofrido por localidades litorâneas em função de processos erosivos foi refletido pela percepção dos usuários da Praia da Taíba. Os resultados obtidos apontaram: 1) O conhecimento no que tange às causas e consequências desse fenômeno; 2) A existência do Terminal Portuário do Pecém como a ação antrópica responsável pela aceleração dos processos erosivos na região; e 3) $\mathrm{O}$ apoio em relação a obras de contenção à erosão costeira por parte do Poder Público.

Diante disso, percebe-se a necessidade de se desenvolverem políticas públicas que visem à melhoria da qualidade da praia e das experiências de recreação, lazer e moradia. Ações visando ao manejo eficiente de resíduos sólidos, à conscientização ambiental, à segurança e ao controle à erosão costeira, bem como uma maior atenção para estudos e programas de monitoramento ambiental em função das interferências do TPP na dinâmica costeira de praias adjacentes.

\section{Agradecimentos}

Os autores agradecem a colaboração de Allyne Ferreira Gama. As imagens concedidas por Ana Lyvia Martins, Igres Dinis e Monalysa Carvalho. Aos revisores da RGCI pelas sugestões e contribuições. 


\section{Referências}

Araújo, R.C.P.; Freitas, K.S.; Albuquerque, R.L. (2009) - Impactos Socioeconômicos do Complexo Industrial e Portuário do Pecém (CIPP) sobre os Pescadores Artesanais, São Gonçalo do Amarante-CE. Anais do $47^{\circ}$ Congresso da Sociedade Brasileira de Economia, Administração e Sociologia Rural - SOBER, Porto Alegre, RS, Brasil. Disponível on-line em http://www. sober.org.br/palestra/13/260.pdf

Araújo, R.C.P.; Maia, L.P. (2011) - Análise dos problemas e objetivos das atividades econômicas tradicionais e emergentes na zona costeira do estado do Ceará. Arquivos de Ciências do Mar (ISSN 0374-5686), XLIV(3):20-39, Fortaleza, CE, Brasil. Disponível on-line em http://www.labomar.ufc.br/ images/stories/arquivos/ArqCienMar/V44_3_2011/acm_2011_4 4_3_03.pdf.

Barros, F.M. Lins de (2005) - Risco, vulnerabilidade física à erosão costeira e impactos sócio-econômicos na orla urbanizada do município de Maricá, Rio de Janeiro. Revista Brasileira de Geomorfologia (ISSN: 2236-5664), 6(2):83-90, São Paulo, SP, Brasil. Disponível on-line em http://www.ugb.org.br/ final/normal/artigos/SEPARATAS_RBG_Ano_6_n_2_2005/RB G_Ano_6_n_2_2005_83_90.pdf

Bird, E.C.F. (1993) - Submerging Coasts: The effects of a Rising Sea Level on Coastal Environments.184p, John Wiley\& Sons, Chichester, UK. ISBN 0471938076.

Bittencourt, N.L.R.; Centenaro, K.S.; Marimon, M.P.C. (2011) - A Percepção Ambiental como Instrumento de Análise da Qualidade Ambiental. Revista Geográfica de América Central (ISSN: 2215-2563), II(47E):1-15, Heredia, Costa Rica. Disponível on-line em http://www.revistas.una.ac.cr/index.php/ geografica/article/view/2674

Calliari, L.J.; Muehe, D.; Hoefel, F.G.; Toldo Jr., E. (2003) Morfodinâmica praial: uma breve revisão. Revista Brasileira de Oceanografia (ISSN: 1413-7739), 51:63-78, São Paulo, SP, Brasil. Disponível on-line em http://www.scielo.br/pdf/ bjoce/v51nunico/07.pdf.

Coriolano, L.N.M. (2008) - Litoral do Ceará: espaço de poder, conflito e lazer. Revista da Gestão Costeira Integrada, 8(2):277287. DOI: $10.5894 / \mathrm{rgci} 131$

Dias Filho, M.; Silva-Cavalcanti, J.S.; Araujo, M.C.B.; Silva, A.C.M. (2011) - Avaliação da Percepção Pública na Contaminação por Lixo Marinho de acordo com o Perfil do Usuário: Estudo de Caso em uma Praia Urbana no Nordeste do Brasil. Revista da Gestão Costeira Integrada, 11(1):49-55. DOI: 10.5894/rgci190

Farias, E.G.G.; Maia, L.P. (2010) - Uso de técnicas de geoprocessamento para a análise da evolução da linha de costa em ambientes litorâneos do Estado do Ceará, Brasil. Revista da Gestão Costeira Integrada, 10(4):521-544. DOI: 10.5894/ $\operatorname{rgci} 224$

Ferla, M.; Lehugeur, L.G.O. (2007) - Avaliação dos impactos ambientais provenientes do uso e ocupação da terra, estudo de caso: Distrito de Taíba, Município de São Gonçalo do Amarante, Ceará. Anais do XI Congresso da Associação Brasileira de Estudos do Quaternário - ABEQUA, Belém, PA, Brasil. Disponível on-line em http://www.abequa.org.br/ trabalhos/2007_marcello_ferla_gerenciamento.pdf

Fernandes, L.G.; Sansolo, D.G. (2013) - Percepção ambiental dos moradores da cidade de São Vicente sobre os resíduos sólidos na Praia do Gonzaguinha, SP, Brasil. Revista da Gestão Costeira Integrada, 13(3):379-389. DOI: 10.5894/rgci416

Friesinger, S.; Bernatchez, P. (2010) - Perceptions of Gulf of St. Lawrence coastal communities confronting environmental change: Hazards and adaptation, Québec, Canada. Ocean \&
Coastal Management, 53(11):669-678. DOI: 10.1016/ j.ocecoaman.2010.09.001

INESP/CAECE (2013) - Cenário Atual do Complexo Industrial e Portuário do Pecém. 128p., Instituto de Estudos e Pesquisas para o Desenvolvimento do Estado do Ceará (INESP) / Conselho de Altos Estudos e Assuntos Estratégicos da Assembleia Legislativa do Estado do Ceará (CAECE), Fortaleza, CE, Brasil. Disponível on-line em http://www.al.ce.gov.br/phocadownload/Cenario_Porto_do_Pec em_15-02-13.pdf

Instituto Brasileiro de Geografia e Estatística - IBGE (2010) - Censo demográfico 2010. Instituto Brasileiro de Geografia e Estatística (IBGE), Rio de Janeiro, RJ, Brasil. Disponível on-line em http://www.ibge.gov.br/home/estatistica/populacao/censo2010/

Magini, C.; Martins, A.H.O; Pitombeira, E.S.; Chaves, Q.L.S.G. (2011) - A influência da estrutura portuária na dinâmica costeira da Vila do Pecém, Ceará, Brasil. Revista de Geologia (ISSN: 0103-2410), 24(2):136-149, Fortaleza, CE, Brasil. Disponível on-line em http://www.revistadegeologia.ufc.br/documents/ revista/2011/11_2011.pdf

Marin, A.A. (2008) - Pesquisa em educação ambiental e percepção ambiental. Pesquisa em Educação Ambiental (ISSN: 2177580X), 3(1):203-222, São Paulo, SP, Brasil. Disponível on-line em http://www.revistas.usp.br/pea/article/view/30047/31934

Morgan, R.; Jones, T.C.; Willians, A.T. (1993) - Opinions and Perceptions of England and Wales Heritage Coast Beach Users: Some Management Implications from the Glamorgan Heritage Coast, Wales. Journal of Coast Research (ISSN 0749-0208), 9(4):1083-1093. Article Stable URL: http://www.jstor.org /stable/4298165

Muehe, D. (2006) - Ministério do Meio Ambiente - Erosão e progradação no litoral brasileiro. In: Dieter Muehe (org.), Erosão e progradação no litoral brasileiro, pp.265-296, MMA, Brasilia-DF, Brasil. ISBN: 8577380289. Disponível on-line em http://www.mma.gov.br/estruturas/sqa_sigercom/_publicacao/7 8 publicacao 12122008084856

Nogueira, M.C.; Augusto, V.A.; Castelo Branco, R.M.G.; Castro, D.L. (2005) - Caracterização Geoambiental e Hidrogeológica da Zona Portuária do Pecém/CE. Revista de Geologia (ISSN: 01032410), 18(2):203-213, Fortaleza, CE, Brasil. Disponível on-line em http://www.revistadegeologia.ufc.br/documents/revista/ 2005/18_2005.pdf

Paiva, F.; Macedo, M. (1997) - Ceará. Guia de Praias. 108p., Edições Fundação Demócrito Rocha, Fortaleza, CE, Brasil. ISBN: 8586375039.

Palma, I.R. (2005) - Análise da Percepção Ambiental como Instrumento ao Planejamento da Educação Ambiental. 101p., Dissertação de Mestrado, Universidade Federal do Rio Grande do Sul, Porto Alegre, RS, Brasil. Disponível on-line em http://hdl.handle.net/10183/7708

Priskin, J. (2003) - Tourist Perception of Degradation Caused by Coast Nature - Base Recreation. Environmental Management, 32(2):189-204. DOI: 10.1007/s00267-002-2916-z

Roca, E.; Villares, M.; Otego, M.I. (2009) - Assessing Public Perceptions on beach quality according to beach users' profile: A case study in the Costa Brava (Spain). Tourism Management (ISSN: 0261-5177), 30(4):598-607. DOI: 10.1016/ j.tourman.2008.10.015

Santana Neto, S.P.; Silva, I.R.; Cerqueira, M.B.; Tinoco, M.S. (2011) - Perfil sócio-econômico de usuários de praia e percepção sobre a poluição por lixo marinho: Praia do Porto da Barra, BA, Brasil. Revista da Gestão Costeira Integrada. 11(2):197-206. DOI: $10.5894 /$ rgci240 
Silva, C.P. (2002) - Gestão Litoral: Integração de estudos de percepção da Paisagem e Imagens Digitais na Definição da Capacidade de Carga de Praias. O Troço Litoral S. Torpes Ilha do Pessegueiro. 339p., Dissertação de Doutorado, Universidade de Lisboa, Portugal. Disponível on-line em http://hdl.handle.net/10362/3651

Sousa, P.H.G.O.; Carvalho, D.A.P.; Pinheiro, L.S. (2008) - A costa de Paracuru: turismo, ocupação e perfil do usuário. Revista da Gestão Costeira Integrada. 8(2): 247-258. DOI: $10.5894 / \mathrm{rgci} 129$

Souza, C.R.G. (2009) - A Erosão Costeira e os Desafios da Gestão Costeira no Brasil. Revista da Gestão Costeira Integrada, 9(1):17-37. DOI: 10.5894/rgci147
Venson, G.R. (2009) - Estudo da Capacidade Física e Social como uma Ferramenta de Gestão Ambiental na Praia Brava do Municipio de Itajai no Litoral Centro-Norte de Santa Catarina. Dissertação de Mestrado, Universidade do Vale do Itajaí, SC, Brasil. Disponível on-line em http://www6.univali. $\mathrm{br} /$ tede/tde_busca/arquivo.php?codArquivo $=670$

Vieira, L.A.A.; Pitombeira, E.S.; Souza, R.O. (2007) - Análise estatística do regime de ondas ao longo da região marítima do porto do Pecém. Anais do XVII Simpósio Brasileiro de Recursos Hídricos, São Paulo, SP, Brasil. Disponível em http://www.abrh.org.br/sgcv3/userfiles/sumarios/8f210dac01f91 c041ff0dc925339d047_89123260e809a99bd064a6121c693681. pdf 